\title{
SOLAR POWER CONCENTRATOR WITH PHOTOELECTRIC SENSOR CONTROL
}

\author{
Imants Ziemelis, Liene Kancevica, Henriks Putans, Viktorija Zagorska, Ilze Pelece \\ Latvia University of Life Sciences and Technologies, Latvia \\ liene.kancevica@1lu.lv, henriksooo@inbox.lv, viktorija.zagorska@1lu.lv, ilze.pelece@1lu.lv
}

\begin{abstract}
The solved problem of the paper is the usage of a parabolic-cylindrical solar concentrator with a cylindrical solar absorber standing on the solar tracking stand previously used for solar photovoltaic panels. The purpose of the work is to prepare a solar-panel follow-up stand with a single-engine double-powered crank mechanism and a photo-electric control sensor for use with a solar-radiation parabol-cylindrical energy concentrator and a cylindrical concentrated solar absorber. In order to clarify and achieve the conformity of the parameters of the sun-tracking stand, the requirements of the parabola-cylindrical energy concentrator parameters were adjusted: photo-electric solar sensor electrical circuit was changed, in power amplifier operational amplifiers with internal frequency adjustments were used. As the principle of periodic rotation is used in the stand mechanism, a sunlight sensor, a mirror and a reflected radiation absorber, a plastic tube was mounted on the stand to determine the duration of the smallest rotation periods (the highest frequency) at which the machine is operating stable. During the experiments, when changing the duration of return periods, the stability of the plant was observed. It turned out that, if the return period is less than one minute, when the cloud covers the sun, the machine tries to turn around and move towards a lighter spot on the horizon, from which the sensor comes to a larger dispersed radiation that the parabolic concentrator does not use in practice. Also, there was determined the instability of the duration of return periods at different settings for the duration of the return period, the amplitude of the deviation (back-to-back) of the reflected radiation band from the mirror on the surface of the absorber during the return period and the minimum width of the mirror.
\end{abstract}

Keywords: solar energy, tracker, absorber with concentrator, photometrical sensor.

\section{Introduction}

Solar trackers can be classified according to various criteria, such as rotation axes number, orientation type, activity type [1].

A lot of different tracking systems are known, and they can be classified as: active solar tracking, passive solar tracking, single axis solar tracker, horizontal axis solar tracker, vertical axle solar trackers, dual axis solar tracker, altitude azimuth solar tracker, two axes mount solar tracker [2].

Since solar tracking panels include moving parts and control elements relatively expensive, the single-axis variant seems to be more cost-effective than the double-axis alternative, or the double drive has to be used for more powerful solar systems [3; 4], therefore, it was decided to simplify the construction by reducing the number of drive engines to one and using the double-powered crank mechanism, and the other innovation of the device is that the tracking system is applied for the parabola cylindrical solar energy concentrator, which changes the calculations of the necessary rotation angles.

This theme is in connection with a Doctoral thesis and is a continuation of the $[5 ; 6]$ issues addressed. For experiments with the air heating equipment, see Fig. 1, which the parabola-cylindrical solar energy concentrator positioned on wheels (1), and concentrated solar radiation absorber placed in focus (2) - a thin-walled aluminium tube with vortex chambers, coated with black matt silicone paint [7], quite high, to $76 \%$ energy transfer efficiency was found. During the experiments, the wheelmounted concentrator with absorber was manually orientated continuously to the sun. Therefore, the experiments were relatively short and insufficient to fully judge the technical capabilities of this equipment. In this regard, it has been decided to place the equipment of concentrator with the absorber and the air supply equipment, after appropriate rearrangement which will be discussed here, on a suntracking stand [6] (Fig. 4) and to take a longer experiment by operating the equipment in automatic sun-tracking mode.

The sun-tracking stand [6] (Fig. 4) and its equipment are intended for rotation and orientation of solar panels, which do not require precise orientation to the sun, because, for example, a normal deviation of the incidence angle of radiation on the solar panel surface decreases the radiation intensity by $\pm 5^{\circ}$ (power, cos angle value) from 1 to 0.996 . However, using a parabolic-cylindrical concentrator at such a deviation the concentrated radiation can go through the cylindrical surface of the absorber. 
Solar-tracking stand (Fig. 4) rotates and focuses the solar energy concentrator periodically. When, during the course of the sun, the radiation on the solar sensor is shifted by a set angle, a voltage is applied to the output terminals of the sensor, which acts on the actuator of the energy concentrator and returns it to the sun. This return frequency determines the walking amplitude of the radiation spot reflected on the absorber tube in the radial direction. The higher is the return frequency, the smaller will be the walking amplitude of the sun spot on the absorber surface and the reflected radiation will remain more perpendicular to the absorber tube radiation. A smaller diameter absorber with a smaller surface and less heat loss can be used. In order to find the highest frequency at which the unit operates steadily, the equipment shown in Fig. 4 was mounted on a stand and subjected to appropriate tests.

In order to improve the equipment parameters, the parameters of the solar sensor and the electric power amplifier of the concentrator drive were improved in connection with the use of the hub. Parabolic parameters are discussed and mathematical expressions used to refine and improve the hub reflector are given.

According to the literature review [8;9] paraboloidal solar energy concentrators with the highest potential capability are capable of focusing at a concentration of $10^{6}$ and a temperature of up to $3000{ }^{\circ} \mathrm{C}$ (practically $2500 \mathrm{x}, \geq 1000^{\circ}$ ). With parabolic-cylindrical concentrators the maximum degree of concentration is 100 times (practically 70 times) and the maximum temperature is $500^{\circ}\left(400^{\circ} \mathrm{C}\right)$. The amount of energy received by the absorber can be significantly reduced by changes in the position and orientation of all elements of the unit during rotation and stationing, which require special attention when arranging the unit.

\section{Materials and methods}

The aim of this work is to prepare a solar panel solar tracking stand [6] with one electric motor double axis drive with a gearbox and a crank mechanism and photo-electric control sensor for operation with a solar parabolic-cylindrical energy concentrator and a cylindrical concentrated solar radiation energy absorber.

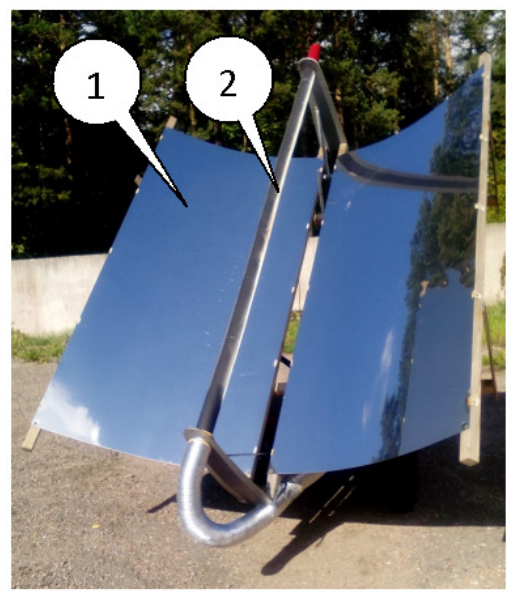

Fig. 1. Air heating equipment: 1 - parabola-cylindrical solar energy concentrator; 2 - tube

In order to improve the stability and accuracy of operation of the existing stand, the following changes have been made to the stand: in the solar tracking motor drive circuit (Fig. 2), the two HPDR3K photodiodes used in the solar sensor are connected in a reverse-to-parallel circuit and loaded with a rope resistor R. As a result of [6], at the same solar radiation intensity on the sun is twice the voltage at the sensor output terminals (Fig. 3), with rapid changes at zero values. The other improvement is: the voltage amplifier uses higher power, newer operational amplifiers with internal frequency correction circuits. The electrical circuit diagram of the amplifiers is shown in Fig. 2, where $\mathrm{R} 1, \mathrm{R} 2$ set normalized gain of each operational amplifier, $K=100$. As in the previous version, the amplifier $U_{i z}$ is connected to an electromechanical relay unit, which, depending on the $U_{i z}$ value, switches on/off the rotary drive motor. 


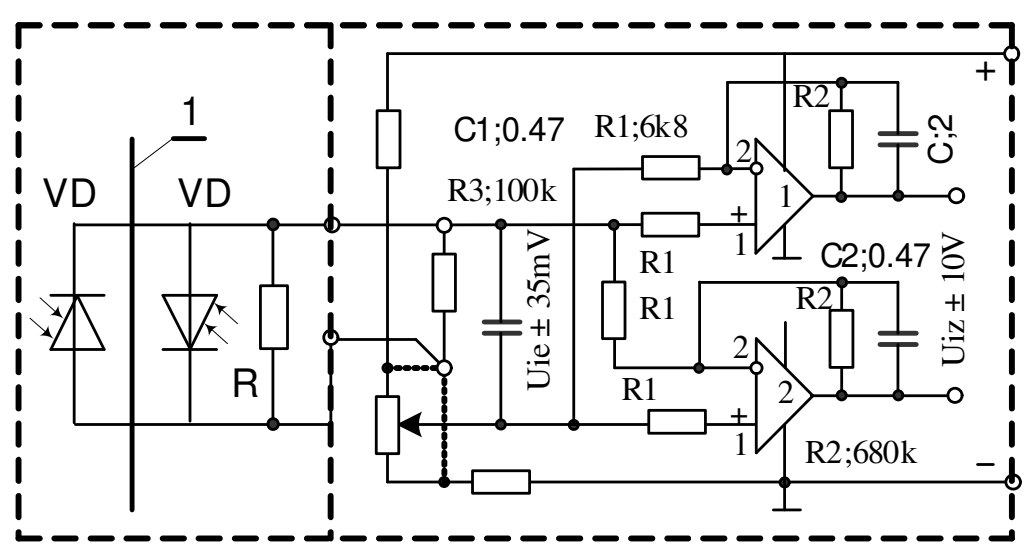

Fig. 2. Electrical circuit of sun tracking motor drive

Due to the periodic operation of the rotating mechanism, an experiment was performed using a tripod with the equipment shown in Figure 4 to determine the deviation of the concentrated radiation band on the absorbent surface during the return period and return frequency. Figure 5 shows the distances between the elements of this equipment. Within one hour, the angle of incidence of sunlight $S$ (Fig. 5) on the mirror surface 4 is shifted to the left by 15 degrees. The radiation reflected on the absorber surface will be deflected to the right (looking in the direction of the radiation) by the same angle. Assuming a maximum return period, the time between two rotation pulses of 2 min, this angle will be $15 / 60 \cdot 2=0.5^{\circ}$ and the deviation of the radiation (spot) band to the absorber to the right (Fig. 4; Fig. 5), $\operatorname{tg} 0.5 \cdot 1280=11.2 \mathrm{~mm}$, which coincides with the values obtained during the experiment.

An experiment was carried out to determine the minimum width of a mirror to be used. For this purpose, one side of the surface of the mirror covered with tape is vertical. It turned out that if the width of the strip of the mirror surface is five millimetres, there is still a clearly visible, contrasting band of radiation about four mm wide on the surface of the absorber.

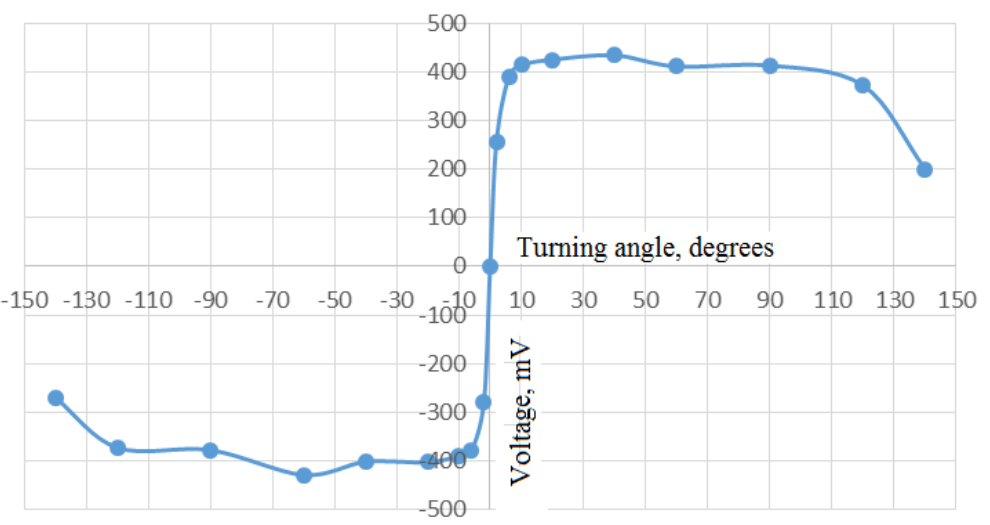

Fig. 3. Voltage on solar sensor output terminals depending on radiation deviation, rotation angle: sun sensor V-A curve, in the sun (September 7, 2019)

During the experiments, the operation stability of the unit was observed by changing the length of the return periods (by slightly tilting or inserting the tops of the solar sensor (Fig. 6) symmetrically slightly into the sockets). If the return period is less than one minute, while the cloud is covering the sun, the machine is trying to rotate and focus on a lighter spot at the horizon, from which the sensor emits more diffused radiation that is virtually unavailable to a parabolic hub. If the return period is greater than one minute, the machine is stable. In the graphs (Fig. 7; Fig. 8), the variations in the length of the return periods (differences) are relatively large and are mainly related to the reduced idle speed in the gear reducer and the elasticity of the stand.

Mirror experiments provide an idea of the possibilities of forming a cylindrical parabola from mirror ribbons and judging the characteristics of individual ribbons in relation to the diameter of the ciliary absorber. As in our case, there are two polished stainless steel sheets, $1 \times 2 \mathrm{~m}$, which in order to obtain maximum concentrated radiation on the absorber must be accurately fitted in the form of a 
parabolic curve. That is, the coordinates of each point on the surface of the sheet must correspond to $y^{2}=2 p x$, Fig. 9, where OE curve is essentially a reflector of the energy concentrator in the cross section, from which the incident point of the surface (elemental mirror) falls below the same angle reflected on the surface of the absorber. As the sun's angle is $32^{\prime}\left(0.53^{\circ}\right)$, the diameter of the focal spot on the absorber will be $\operatorname{tg}(0.53)^{\circ} \cdot L$, where $L$ - is the distance from the parabolic reflector to the absorber. For example, if $L=650 \mathrm{~mm}$, then theoretically, $D=0.0092 .650=6 \mathrm{~mm}$. In practice, in the experiments [9], the reflector used in Fig. 1 had a focal bandwidth of about $4 \mathrm{~cm}$ on the absorber, which means that its parameter can be significantly improved. Fig. 9 gives the most important parabolic parameters and expressions $1-4$, which can be used to rearrange the reflector of the parabolic-cylindrical solar energy concentrator.
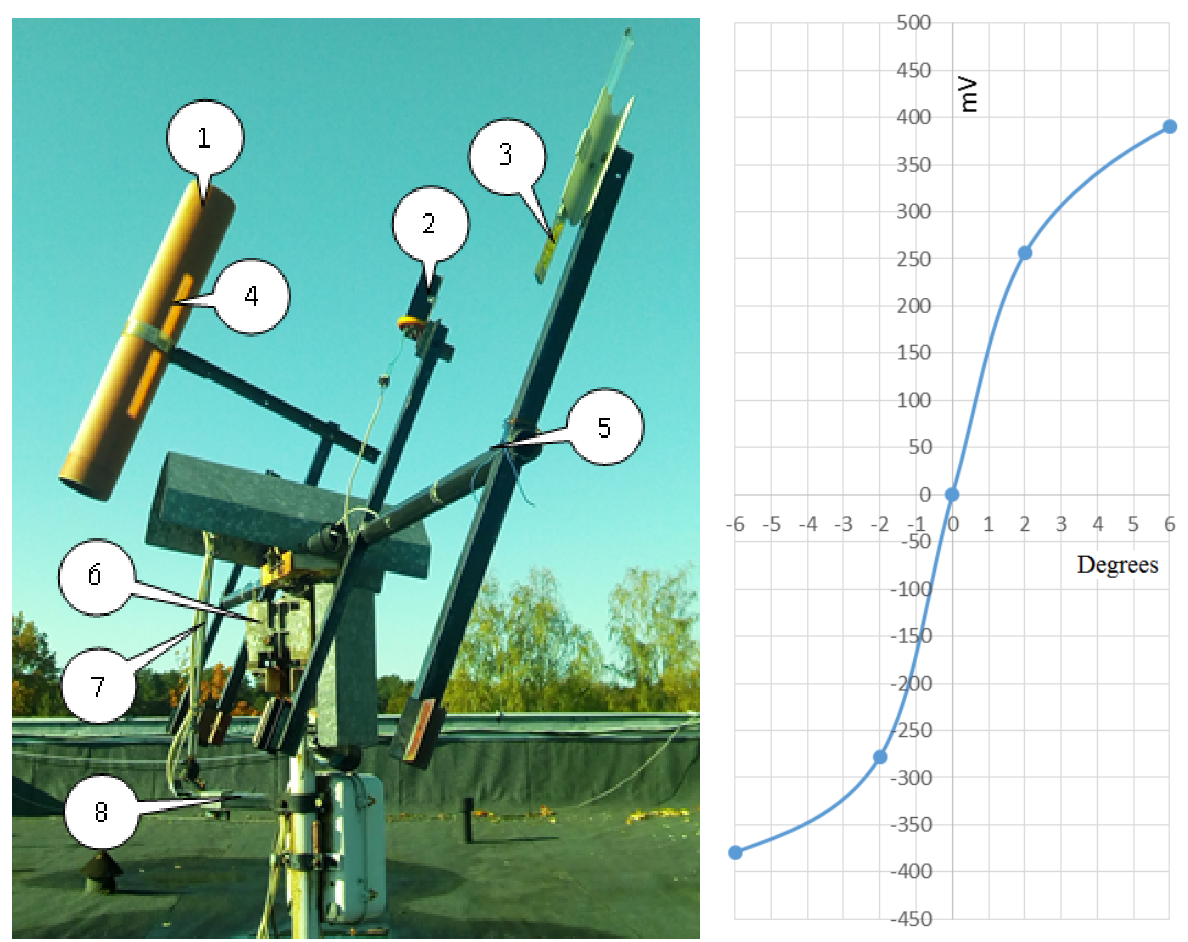

Fig. 4. Equipment used for evaluation of equipment stability and radiation deflection: 1 - mirror reflector absorber, plastic tube, $\mathrm{D}=110 \mathrm{~mm} ; 2$ - solar sensor with two HPDR3K photodiodes; 3 - mirror, width, 23mm; 4 - concentrated radiation band (focal spot), width $25 \mathrm{~mm}, 5$ - frame; 6 - gearbox reducer; 7 - clan of gearbox and a crank mechanism; 8 - connecting rod end bracket; solar sensor $\mathrm{V}$-A curves in the 0 value range (on the right)

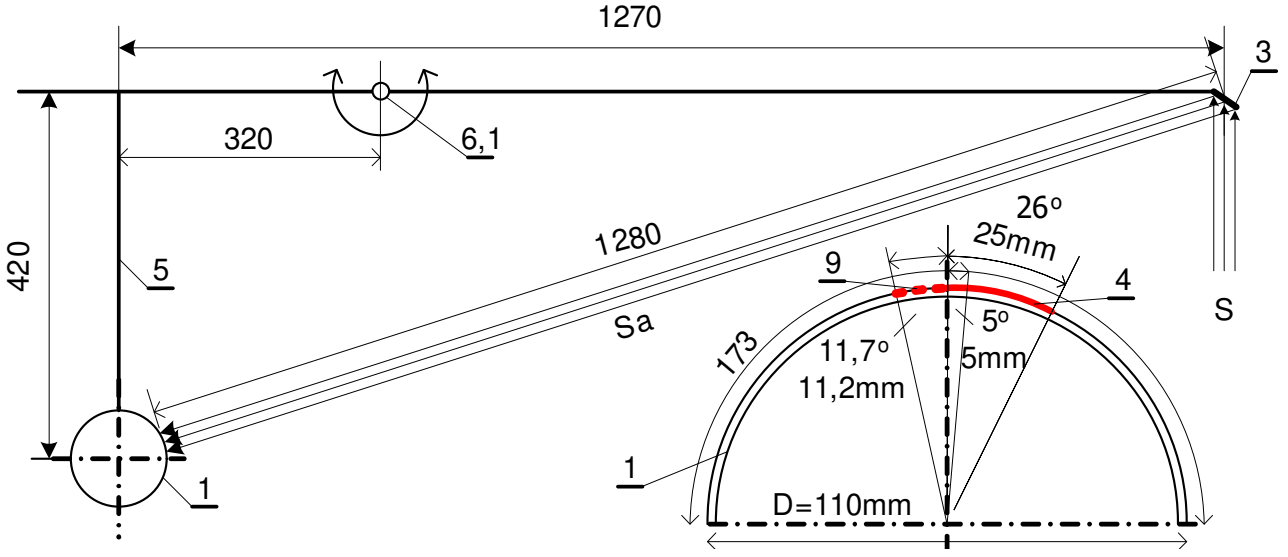

Fig. 5. Parameters of the equipment (Fig. 4) obtained in experiments and calculations: $S$ - solar radiation on the mirror; $S_{a}$ - radiation reflected from the mirror; 1 - plastic tube for reflection bsorber; 3 - mirror, width, 23mm; 4 - concentrated radiation band (focal spot), width $25 \mathrm{~mm} ; 6.1$ - secondary shaft of the gear unit 6 (Fig. 4); 9 - deviation zone of the concentrated radiation band 4 within two min 


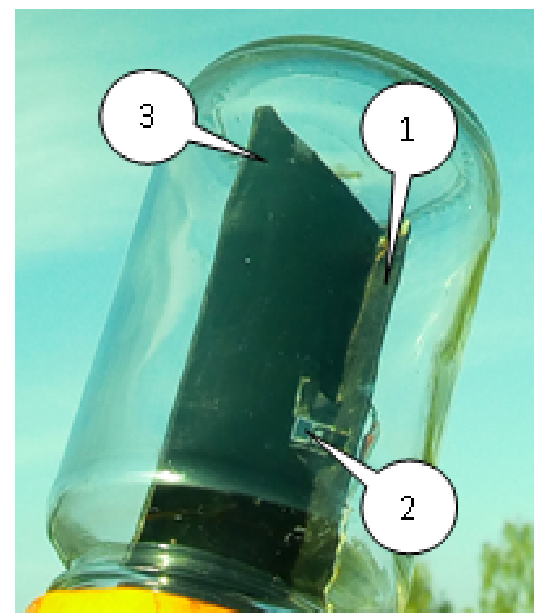

Fig. 6. Solar sensor design, circuit diagram (Fig. 2): 1 - base; 2 - HPDR3K photoelectric diodes, one on each side of the plate; 3 - radiation separation plate

Parabolic equation:

$$
\begin{gathered}
y^{2}=2 p x \\
f y=A B S(A 1 * 2 * p)^{\wedge} 1 / 2
\end{gathered}
$$

where $A 1-$ column with $\mathrm{x}$ values;

$p$ - parabola parameter and equal to two focal lengths to the parabola curve, if $y=0$.

Coordinates of a point on the tangent:

$$
y_{0} y_{i}=p\left(x_{0}+x_{i}\right)
$$

Assuming value $\mathrm{x}_{\mathrm{i}}$,

$$
y_{i}=p\left(x_{0}+x_{i}\right) / y_{0}
$$

\section{Results and discussion}

By connecting the solar sensor diodes in the reverse-parallel circuit (Fig. 2) with one common resistor, the electrical circuit diagram of the sensor is simplified and the sensor parameters are greatly improved: the voltage at the sensor terminals (Fig. 3) increased to $\pm 400 \mathrm{mV}$, voltage increase rate around zero value $-125 \mathrm{mV}$ per degree of solar deflection. The power amplifier uses operational amplifiers with internal frequency correction, current and voltage protection circuits, which significantly improves the drive stability and safety. As already stated, the solar tracking stand discussed in Fig. 4 rotates and focuses the solar energy concentrator periodically. When the solar radiation is directed at a certain angle to the solar sensor, a voltage is applied to the sensor output terminals, which when actuated by the tripod drive mechanism return the solar sensor with all rotating tripod equipment to the output position. The frequency of these returns is basically determined by two factors, the steepness of the solar sensor curve at zero output voltage and the gain of the voltage amplifier. In our case, the gain is 100 , the relay switching voltage is $10 \mathrm{~V}$, which means that if the solar sensor output voltage reaches $100 \mathrm{mV}$, the return process will start and continue until the sensor output voltage drops to 0. When looking at the solar sensor's VA characteristics (See Fig. 4) that for the voltage at the solar sensor terminals change from 0 to $100 \mathrm{mV}$, the incident angle of the solar radiation must change by 0.6 degrees, which is equivalent to $2.4 \mathrm{~min}$ or $144 \mathrm{~s}$. This time is about twice as long as the values in Fig. 7, with an average return time of about $70 \mathrm{~s}$, which provided stable operation of the unit. The observed difference in time is due to the fact that the voltage on the terminals of the solar sensor decreases when the unit returns to the initial state. This also reduces the voltage on the relay, which switches on and off and brakes the drive motor. As the relay cut-off voltage is high relative to the relay turn-on voltage, the relay shuts off the motor before returning to the output state before the output of the solar sensor is zero. Consequently, the voltage at the sensor terminals can be permanently higher than zero at the output. 
02.08.19.

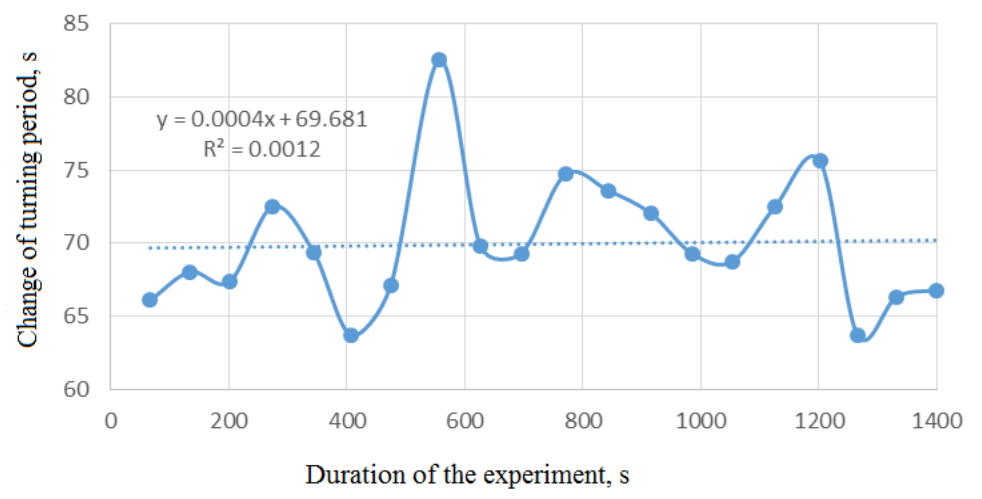

Fig. 7. Fluctuations in length of rotation periods

27.09.2019

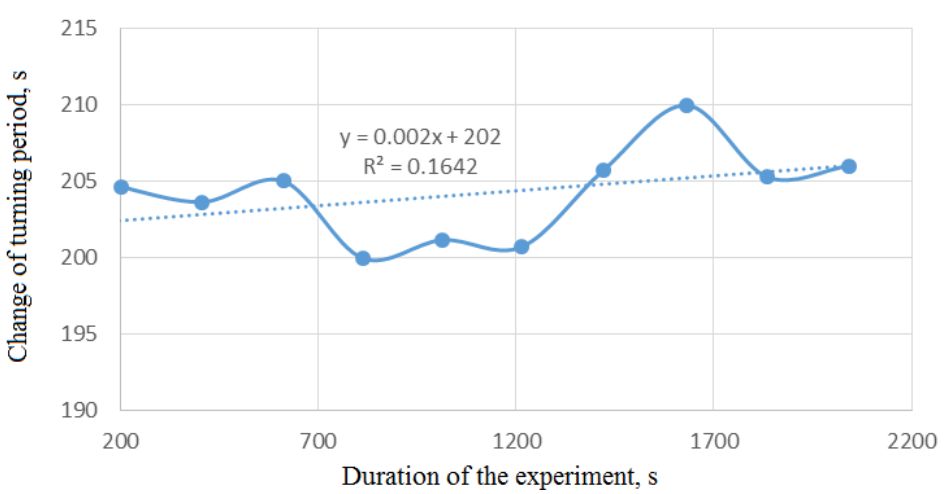

Fig. 8. Fluctuations in the duration of the rotation periods after the state of the diodes (Fig.6)

By slightly folding the tops of the solar sensor diodes, the characteristic curve of Fig. 3 has been changed and the return period of the unit has been increased to $3.4 \mathrm{~min}$.

In order to obtain the highest possible energy transfer coefficient, the reflecting surface of the hub must be curved symmetrically on both sides of the focus according to the parabolic law $y=(2 p x)^{0.5}$, which is depicted in this connection in Figure 9 and discussed extensively enough to be used in checking and restoring an existing hub.

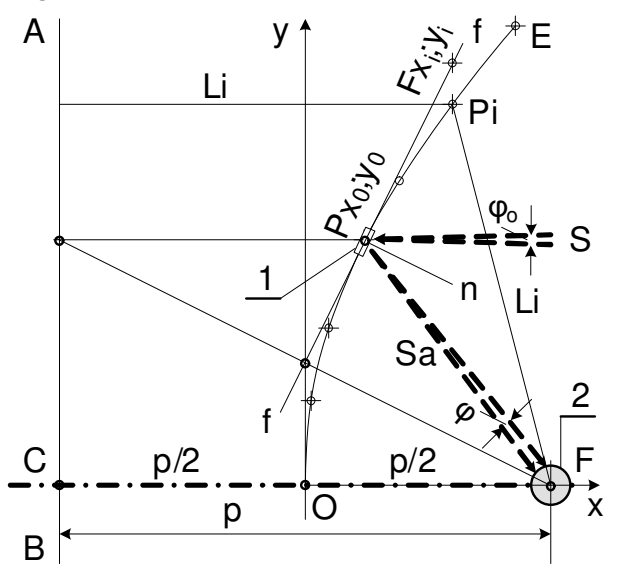

Fig. 9. Parabola characteristics: $A B$ - director; $F$ - focus; $p$ - parameter of the parabola; 1 - mirror (mirror element); 2 - absorber; $L i$ - equidistant distances from the point on the parabolic surface to the focus $F$ and the directrix $A B ; p / 2-$ focal length; $\varphi_{o}$ - angle of the sun $=32^{\prime}=0.53^{\circ} ; \varphi$ - radius of incident spot on the absorber 2; OE - parabola; $f-f$ - tangent to the parabola at $P_{x 0 ; y 0} ; S$ - sun ray;

$S a$ - reflected beam; $P, F$ - points with coordinates on the parabolic tangent $f-f$ at point $P$;

A parabola is a series of dots that are equidistant from directivity and focus. Coordinates of the parabola curve are given in Table 1. 
Coordinates of the parabola curve, $p=100$

Table 1

\begin{tabular}{|c|c|c|c|c|c|c|c|c|c|c|c|c|}
\hline $\boldsymbol{x}$ & 0.0 & 2.5 & 5 & 10 & 15 & 20 & 25 & 30 & 35 & 40 & 45 & 50 \\
\hline $\boldsymbol{y}$ & 0.0 & 22.36 & 31.62 & 44.72 & 54.77 & 63.24 & 70.71 & 77.46 & 83.67 & 89.44 & 94.87 & 100 \\
\hline
\end{tabular}

\section{Conclusions}

1. The aim of this work is to prepare a solar tracking unit for solar panels [6] with a single-engine dual-axis slider-crank mechanism and a photo-electric control sensor for operation with a parabolic-cylindrical solar energy concentrator and a cylindrical concentrated solar radiation absorber.

2. Two HPDR3K photodiodes used in a solar sensor to reverse the operation of the existing tripod were connected in reverse and loaded with a resistor. As a result, at the same solar radiation intensity, double value of the voltage at the output terminals of the solar sensor was obtained with a rapid voltage change from zero to $160 \mathrm{mV}$ per degree of radiation deflection compared to the current variant.

3. The sensor voltage amplifier uses higher power operational amplifiers with internal frequency correction, current and voltage protection circuits. For amplifiers, the voltage amplification coefficient, $K=100$, is schematic.

4. During the experiments, changing the duration of the return periods (by slightly tilting or sliding the tops of the solar sensor (Fig. 6) diode symmetrically into the sockets) repeatedly was observed the operational stability of the unit. No malfunctions were observed at the return period of $70 \mathrm{~s}$, (Fig. 7). If the return period is less than one minute, the device tries to rotate and focus on the brighter spot, the diffused radiation at the horizon.

5. In order to obtain the highest energy transfer coefficient, the reflector surface of the concentrator must be symmetrical on both sides of the focus, when viewed in cross-section and must be concave according to the law of the parabola $y=(2 p x)^{0.5}$, which is depicted in Fig. 9 in this connection and discussed sufficiently broadly to be used in testing and rebuilding an existing concentrator.

\section{References}

[1] Tudorache T., Oancea C.D., Kreindler L. Performance evaluation of a solar tracking PV panel. University "Politehnica" of Bucharest Scientific Bulletin, Series C: Electrical Engineering, 74(1), 2012.

[2] Rizk, J., \& Chaiko, Y. Solar Tracking System: More Efficient Use of Solar Panels. World Academy of Science, Engineering and Technology International Journal of Electrical and Computer Engineering, Vol:2, No:5, 2008, pp. 784-786.

[3] Mousazadeh H., Keyhani A., Javadi A. et al. A review of principle and sun-tracking methods for maximizing solar systems output. Renewable and Sustainable Energy Reviews, 13, pp.1800-1812.

[4] Nader Barsoum, Pandian Vasant (2010) Simplified Solar Tracking Prototype, Global Journal of Technology and Optimization 1, 2009, pp. 38-45.

[5] Ziemelis I., Putans H., Jasinskas A. etc. Investigation of air heating solar collector with energy concentrator. Proceedings of International Conference "Engineering for Rural Development", May 25-27, 2016, LLU, Jelgava, Latvia, pp. 312-317.

[6] Putans H., Ziemelis I, Pelece I. etc. Solar tracking stand for solar panels and collectors. Proceedings of International Conference "Engineering for Rural Development", May 23 - 25, 2018, Latvia University of Life Sciences and Technologies, Jelgava, Latvia, pp. 1734-1739.

[7] Latvijas patents, LV15142 a (04.03.16). Ierīce gaisa sildīšanai ar saules enerğiju (Solar air heater) Latvian patent LV15142 a (04.03.16). (In Latvian).

[8] Стребков Д.С., Тверьянович Э.В. Концентраторы солнечного излучения (Solar concentrators), ГНУ ВИЭСХ, Москва, 2007, 315 стр. (In Russian).

[9] Кирюшатовю К.А. Использование нетрадиционных воэобнавляющихся исгочников энергии в сельскохозяйственном произволствею (The use of non-traditional source of energy sources in agricultural arbitrariness). - м.: Агропромиздат, 1991. - 96 c. ISBN 5-10-001454-7. (In Russian). 